\title{
The Role of Interfragmentary Compression Screw on Union Rates and Shortening of the First Ray in Lapidus Arthrodesis: A Comparative Study
}

\section{André Busch*, Marcus Jäger, Florian Dittrich, André Sander, Stephanie Herbstreit and Sascha Beck}

Department of Orthopaedics and Trauma Surgery, University of Duisburg-Essen, Germany

*Corresponding author: Dr. med André Busch, Department of Orthopaedics and Trauma Surgery, University of DuisburgEssen, Hufelandstr, 55, D-45147 Essen, Germany, Tel: +49-201-723-1300, Fax: +49-201-723-5910

\section{Introduction}

Hallux valgus (HV) is a common deformity of the forefoot in which a deviation of the first metatarsophalangeal joint arises. HV has been described to be characterized by a number of structural factors including radiographic angles, metatarsal length, metatarsal head shape, sesamoid position, first metatarsocuneiform joint flexibility and pes planus [1-5]. The etiology is not fully resolved. However, HV is associated with gender, age and family history. Moreover, it is limited to shoe-wearing cultures and dependent on footwear in adolescence and adulthood $[6,7]$.

Pathophysiologically, hyperlaxity in the first tarsometatarsal joint, hypermobility of metatarsal bone and muscle imbalance contribute to the emergence of hallux valgus deformity $[8,9]$. Though, the clinical evidence of tarsometatarsal joint hyperlaxity is difficult. In severe forms hypermobility of the metatarsal bone can lead to a dislocation or even to a luxation in the metatarsophalangeal joint [10]. Cadaveric studies indicate that first ray mobility can be reduced by a proximal crescentic osteotomy and distal soft tissue reconstruction (DSTR) without tarsometatarsal fusion $[11,12]$.

Patients suffer from manifold symptoms including pain in the bunion area, lack of space for the other toes due to the deviation of great toe leading to transfer metatarsalgia and pseudo bursitis. On radiographs an increase of the intermetatarsal angle and a deviation of first ray alignment can be observed $[2,7,11]$.

Multiple treatment algorithms including distinct surgical procedures such as Scarf or Chevron type of osteotomies, arthrodesis or soft tissue techniques have been published during the last decades $[13,14]$.

Within these, the Lapidus arthrodesis (LA) represents a surgical option for treatment of moderate and severe hallux valgus deformity in the setting of a hypermobile first ray [15-18]. LA involves fusion of first tarsometatarsal (TMT1) joint with an additional distal bony and soft tissue procedure [19-23]. Non-union rates of LA are reported with up to $12 \%$ in the literature $[8,10,12]$.

The purpose of this retrospective study was to reveal the clinical and radiographic outcomes in two patient cohorts being treated with two modifications of interfragmentary screw placement in the LA. The issue was how much hard-ware and how much stability is necessary in LA in terms of union rates. Another focus was on determination of shortening of the first ray after LA.

\section{Patients and Methods}

Between 2011 and 2013 a total of 62 patients (64 feet) suffering from mild to severe hallux valgus deformity were treated surgically using the Lapidus procedure.

Citation: Busch A, Jäger M, Dittrich F, Sander A, Herbstreit S, et al. (2019) The Role of Interfragmentary Compression Screw on Union Rates and Shortening of the First Ray in Lapidus Arthrodesis: A Comparative Study. Int J Foot Ankle 3:024.

Accepted: February 16, 2019; Published: February 18, 2019

Copyright: (c) 2019 Busch A, et al. This is an open-access article distributed under the terms of the Creative Commons Attribution License, which permits unrestricted use, distribution, and reproduction in any medium, provided the original author and source are credited. 
All patients had failed conservative treatment (physiotherapy, orthosis) and showed none or mild degenerative changes in the metatarsophalangeal joint on standard $\mathrm{x}$-rays (Kellgren-Lawrence grades I and II).

Exclusion criteria were previous trauma and surgery of the affected foot, severe degenerative changes in the metatarsophalangeal joint (Kellgren-Lawrence grades III and IV) and foot malformations in childhood.

Prior to surgery all individuals were positioned supine on the operating table with a cushion under the ipsilateral buttocks and a calf tourniquet was used for hemostasis. The skin was incised on the medial aspect of the first ray reaching from the metatarsophalangeal joint to the medial cuneiform. The TMT1-joint capsule was incised on the medial side and a partial release of the anterior tibial tendon fibres at the first metatarsal base was obtained protecting the main insertion of the tendon at the medial cuneiform. To expose the tarsometatarsal joint space a Hintermann distractor was inserted. The cartilage of the first metatarsal base was resected using an oscillating saw. The metatarsal was held in correction and an appropriate amount of cartilage and bone was resected at the medial cuneiform to obtain an orthograde and slightly plantar flexed TMT1 arthrodesis. The bony surfaces were then reduced and maintained by temporary applied $1.6 \mathrm{~mm}$ K-wires. Proper alignment was checked radiographically. In all patients, a plantar plate (Plantar Lapidus Plating System, DARCO ${ }^{\circledR}$, Wright Medical, Memphis, TN) served for internal fixation of the LA.

In the first cohort an additional extraplate screw (EPS) (DARCO ${ }^{\circledR}$ Wright Medical, Memphis, TN) placed prior to the plantar plate was applied to obtain compression of the arthrodesis gap. Crossing the arthrodesis the screw was directed from the dorsomedial aspect of the first metatarsal base into the medioplantar region of the medial cuneiform.

In the second cohort the distal non-locking screw of the plantar plate was placed across the arthrodesis gap to obtain compression (intraplate screw, IPS). To ensure proper plate and screw positioning biplane radiographs were performed (Figure 1 EPS and Figure 2 IPS).

Furthermore, a distal soft tissue procedure was added in all cases. At the medial side after skin incision neurovascular structures were explored. After t-shaped capsular incision bunion was removed under protection of sesamoid slide bearing. The medial metatarsosesamoid ligament and medial collateral ligament were explored and capsular plication was done.

At the lateral side the skin was incised in first interdigital space. The adductor hallucis aponeurosis was intersected and a tenotomy at the basis of proximal phalanx was performed. The capsule was released at the upper edge of lateral sesamoid bone until full adjustment of sesamoidal subluxation is attained.

An Akin-osteotomy was additionally performed if signs of hallux valgus interphalangeus were present. A modified Chevron osteotomy was carried out in cases with incongruity of the first metatarsophalangeal joint indicated by an increased distal metatatarsal articular angle.

Active and passive mobilization started one day after surgery using a forefoot relief shoe orthosis for a total of 6 weeks. To promote soft-tissue healing patients

\section{Intraplate Screw}

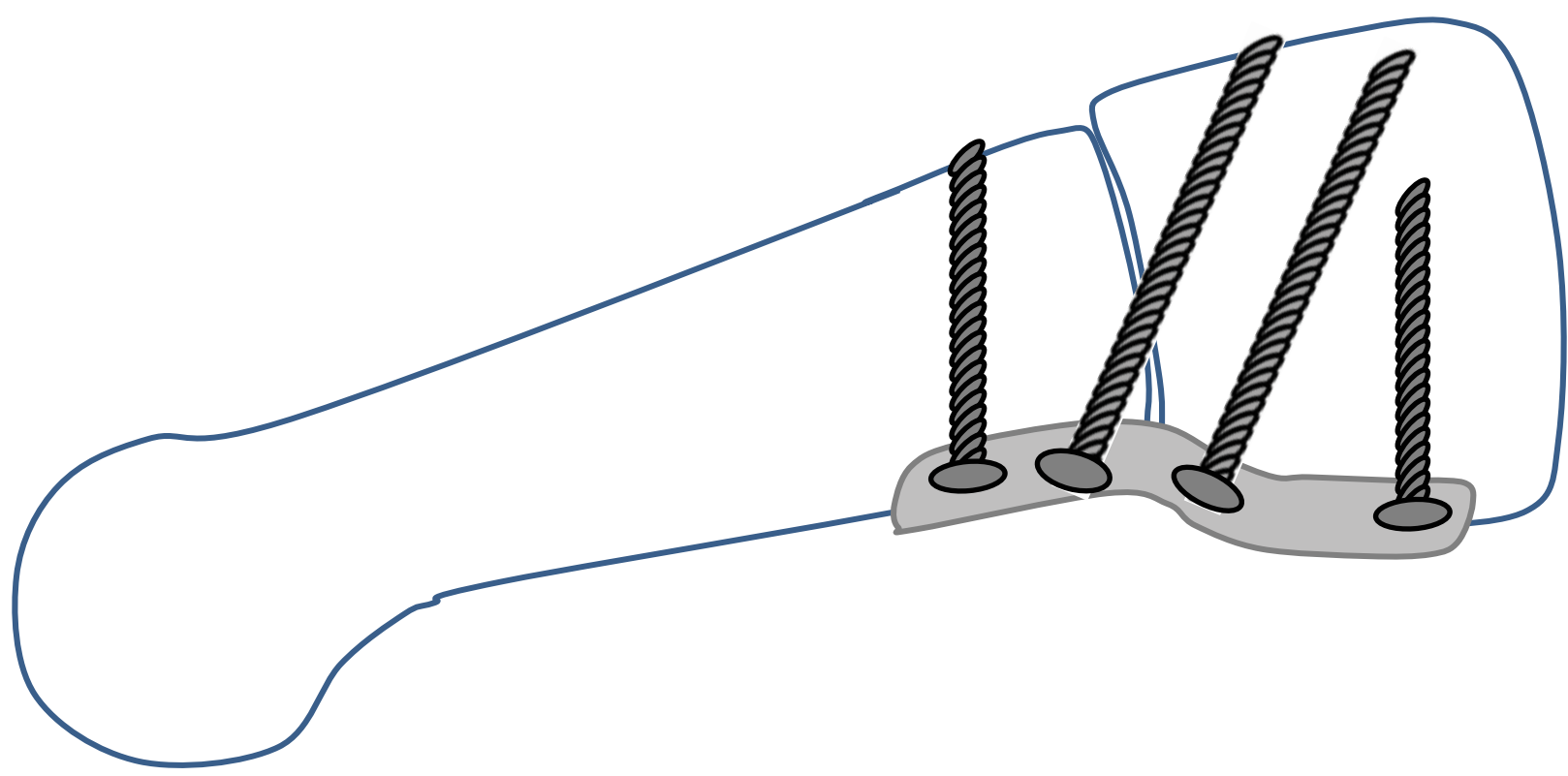

Figure 1: Modified Lapidus arthrodesis with plantar plate. The distal non-locking screw is placed retrograde across the osteotomy gap [20]. 


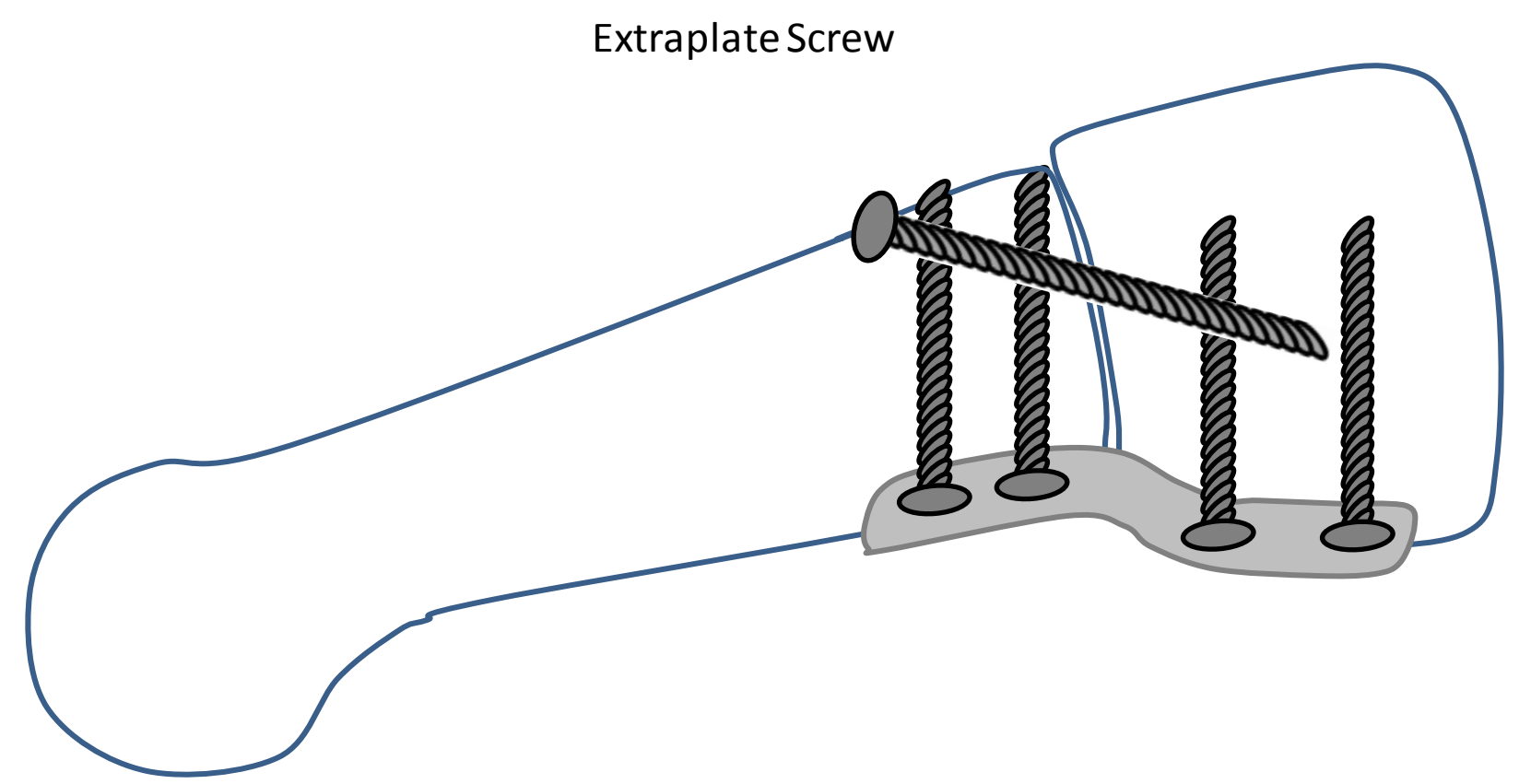

Figure 2: Modified Lapidus arthrodesis with plantar plate and extraplate compression screw [11,20,23].

Table 1: Demographic data of both cohorts; BMI = Body mass index. Male.

\begin{tabular}{|l|l|l|}
\hline \multicolumn{1}{|c|}{} & IPS & EPS \\
\hline $\begin{array}{l}\text { Gender } \\
\text { Male/Female }\end{array}$ & $0 / 12$ & $2 / 18$ \\
\hline Nicotin Abuse \% & $58(7 / 12)$ & $50(10 / 20)$ \\
\hline Systemic Immunsuppresion \% & $8(1 / 12)$ & $5(1 / 20)$ \\
\hline BMI $\left(\mathrm{kg} / \mathrm{m}^{2}\right)$ & $27.5 \pm 3.5$ & $26.7 \pm 3.1$ \\
\hline Systemic anti coagulation \% & $8(1 / 12)$ & $20(4 / 20)$ \\
\hline Age at Surgery $(\mathrm{y})$ & $56.9 \pm 15.9$ & $59.8 \pm 15.4$ \\
\hline Left/Right & $5 / 7$ & $10 / 10$ \\
\hline
\end{tabular}

were requested to keep to partial weight bearing with $20 \mathrm{~kg}$ on crutches for 2 weeks postoperatively followed by transition to full weight bearing. Patients were encouraged to do active ankle exercises in the supine position to aid in reduction of soft-tissue swelling. Six weeks after surgery bone healing was checked radio graphically in standard planes and full-weight bearing was recommended.

There were no significant differences in demographic data between the cohorts (Table 1).

The study was reviewed by the local Ethics Committee (study number 17-7441-BO) and informed consent was obtained from all individual participants included in the study.

Outcome and patient satisfaction were evaluated using the AOFAS and FADI scores as well as weight bearing dorsoplantar and lateral radiographs of the affected foot. Furthermore, tangential radiographs of the sesamoid bones were taken.

The Intermetatarsal Angle (IMA), Hallux Valgus Angle (HVA) and Tibial Sesamoid Position (TSP) were evaluated. The length of the first ray was measured with a modification of the Hardy and Clapham's method. Their method is based on the measurement of the distance between two arcs created from a line between calcaneocuboid joint and medial tuberosity of navicular crossing that of second metatarsal line to the apex of first and second metatarsals [24]. Due to different magnification factors in the $x$-rays we did not only determine the absolute values, but for comparative purposes we also created a quotient of the absolute values to obtain comparable data.

In order to prevent accidental and systematic errors, radiographic evaluation was performed by two blinded surgeons on a single day and repeated in a random order. Non-union was defined as lesser than 3 cortical bridges on anteroposterior and lateral radiographs 6 months after surgery.

\section{Statistical Analysis}

Summary statistics of the data were expressed as mean \pm SD. The Shapiro-Wilk test was used to test for normal distribution. The paired Student's t-test was used for comparison of the normal distribution of preand postoperative means and the Wilcoxon signed-rank test for non-normal distribution. The comparisons with p-values $<0.05$ were considered to be significant. The software SPSS 19 (SPSS Inc. Headquarters, Chicago, Illinois, USA) was used to carry out the statistical computations.

\section{Results}

Of the 62 patients treated with a LA 30 individuals ( 32 feet) were available for a complete follow-up. Moreover, 17 were available only for telephone interview, whereas 15 were lost for follow-up.

The IPS-group consisted of 12 patients available for clinical and radiographic follow-up. The EPS group 
Table 2: Scores prior and after surgery.

\begin{tabular}{|c|c|c|c|}
\hline Score & IPS & EPS & Significance (p-value) \\
\hline AOFAS preoperative & $42.9 \pm 16.8$ & $53.3 \pm 16.2$ & 0.897 \\
\hline AOFAS at follow-up & $86.8 \pm 11.3$ & $86.3 \pm 12.1$ & 0.450 \\
\hline FADI preoperative & $46.8 \pm 16.1$ & $58.0 \pm 16.6$ & 0.680 \\
\hline FADI at follow up & $78.4 \pm 14.1$ & $82.9 \pm 16.0$ & 0.781 \\
\hline
\end{tabular}

Table 3: Radiographic angles for IPS and EPS; $1^{\text {st }}$ IMA = first intermetatarsal angle, HVA = Hallux valgus angle.

\begin{tabular}{|l|l|l|}
\hline \multicolumn{1}{|c|}{ EPS } & IPS \\
\hline HVA preoperative & $44.9 \pm 8.3$ & $41.1 \pm 9.0$ \\
\hline $1^{\text {st }}$ IMA preoperative & $19.5 \pm 6.3$ & $17.7 \pm 6.6$ \\
\hline HVA postoperative & $19.1 \pm 10.0$ & $17.5 \pm 8.3$ \\
\hline $1^{\text {st }}$ IMA postoperative & $8.6 \pm 3.5$ & $7.7 \pm 4.5$ \\
\hline
\end{tabular}

was composed of 20 patients available for clinical and radiographic follow-up. 15 patients were only available for telephone interview.

The first metatarsal bone was additionally adjusted by a modified Chevron osteotomy in 7 of 32 cases (22\%). An Akin osteotomy was performed in 12 of 32 cases (38\%). To correct dactyl malalignments Weil osteotomies were carried out in one or more lesser toes in 20 of 32 cases (63\%).

The average follow-up was $42.5 \pm 21.9$ (29-74) months. There was no significant difference in the follow-up period ( $p=0.19$ ) between the two cohorts.

The mean scores being surveyed prior and after surgery are presented in table 1 . In all scores the patients achieved a significant $(p<0.001)$ improvement after surgery (Table 2).

On the basis of complete documentation radiographic analysis was performed in 32 cases before and after surgery. The mean intermetatarsal angle changed from $18.8^{\circ}$ preoperative to $8.3^{\circ}$ after surgery $(p<0.001)$. The hallux valgus angle was reduced from $43.5^{\circ}$ to $18.3^{\circ}$ on average $(p<0.001)$. Concerning radiographic improvements in intermetatarsal and hallux valgus angle no differences between the IPS-or EPS-cohort could be observed ( $p=0.66$ and $p=0.59$ ) (Table 3 ).

A bunion recurrence was found in 5 (16\%) cases (EPS = 3; IPS = 2). Radiographic signs of ostearthritis in metatarsophalangeal joint exacerbated in 4 (13\%) (EPS $=3$; IPS $=1$ ) cases. The tibial sesamoid bone position improved from $5.3 \pm 1.3$ to $3.6 \pm 1.5$ on average according to the classification of Hardy and Clapham (EPS: $5.5 \pm 1.4$ to $3.9 \pm 1.6$; IPS: $4.8 \pm 1.4$ to $2.9 \pm 1.2 ; p=0.67$ ) . There was a significant shortening of the first ray after surgery from 1.04 to $1.01(p<0.01)$. No significant difference in first ray shorting could be observed comparing the EPS and IPS cohorts (EPS: $1.05 \pm 0.03$ to $1.02 \pm 0.03$; IPS: 1.04 \pm 0.03 to $1.02 \pm 0.03 ; p=0.58$ ).

Revision surgery was necessary in 2 cases due to nonunion of the Lapidus-Arthrodesis (6\%). There was one nonunion case in each cohort meaning a nonunion rate of $8 \%(1$ of 12$)$ in the IPS group and $5 \%(1 / 20)$ in the
EPS group $(p=0.57)$.

\section{Discussion}

Since its first description, many modifications of the Lapidus arthrodesis (LA) have been developed to improve its results [14]. The Lapidus procedure is wellestablished and patient satisfaction is reported to be high [25]. Yet, LA is connoted with high non-union rates. In the past crossed screw fixation has been outlined to be a reliable technique for fusion of the tarsometatarsal joint $[10,15,26,27]$.

In recent years cadaveric studies demonstrated nonuniform results. Roth, et al. (2014) showed that plantar plate fixation created a stronger and stiffer construct than intramedullar fixation [28]. On the contrary, Baxter, et al. claimed that traditional, lagged cross-screws provide greater stability compared to a dorsally placed compression plate [25]. Garas, et al. stated that the addition of a lag screw to plate osteosynthesis extends the maintenance of compression in tarsometatarsal arthrodesis [29]. Recent studies demonstrate that the plantar plate position is superior to the dorsomedial position [15-18,30].

First clinical studies report on suitable stability and an acceptable level of complications of combined plate and intramedullary fixation [31,32].

The topic of fixation technique in arthrodesis and trauma has been subject of debate for a long time. The current data situation is inconsistent. There are reports presenting divergent views about intra and extramedullary fixation concerning non-union rates and clinical outcome [33-36].

We compare two modifications of the Lapidus procedure based on the same study design. Finally, we introduce a new modification of the LA.

We compare two methods to fuse the first tarsometatarsal joint. The first method includes a combination of intra- and extrameduallary osteosynthesis via plantar plate and single lag screw. The other method consists of plantar plate osteosynthesis. One screw was placed retrograde and interfragmentary.

The question about the optimal fixation technique in Lapidus procedure still remains unclear and under investigation. The primary criterion is the creation of maximum initial stability. Failing that, micro movements can result in pseudarthrosis. In addition, surgeons intend to use as little foreign material as possible. This is because foreign material may harm local blood supply 
of the bone and increases infection rate. In addition, economic aspects required consideration.

In the majority of our patients union of TMT-1-arthrodesis could be achieved without any complications. Nevertheless, in 6\% (2/32) symptomatic pseudarthrosis occurred and revision surgery was indicated. The non-union rates observed are comparable to the rates reported in literature quoted between 5 and 12\% $[8,10,12,15,37]$. Comparing the two modifications (IPS and EPS) of the LA no difference in union-rates could be observed. Regardless of the surgical technique applied we have found significant shortening of the first ray postoperatively without any significant differences between the two groups.

From this point of view there is space for improvement of our technique. The application of cancellous autologous bone grafts might help to reduce non-union rates and reduce the amount of postoperative shortening of the first ray. Bone graft is a frequently used technique in foot and ankle surgery. Due to high complication rates in ipsilateral iliac crest as donor site, there is an increasing evidence to harvest cancellous bone graft from ipsilateral tibia or calcaneus [38,39]. Mani, et al. underlined the benefits of bone grafting to reduce non-union rates [10].

\section{Conclusion}

Clinical and radiographic outcome as well as complication rates of the two surgical modifications (EPS and IPS) showed no significant differences. Thus we conclude that there is no benefit of an extraplate lag screw in LA. Plantar plating with an intraplate compression screw seems to provide enough compression on the surfaces and stability for the arthrodesis. However, further studies with higher case numbers have to be conducted to clarify the role of the interfragmentary lag screw.

\section{Limitations}

We have to concede that our study has some limitations. The main limitation is the small number of patients and the loss of follow-up of a large percentage of patients. 15 patients were only available for telephone interview. 10 patients were lost for follow-up and 5 patients died from diseases not related to the Lapidus surgery prior to follow-up.

This research did not receive any specific grant from funding agencies in the public, commercial, or not-forprofit sectors.

Ethics approval and consent to participate: The study was reviewed by the local Ethics Committee (study number 17-7441-BO) and informed consent was obtained from all individual participants included in the study.

\section{Consent to Publish}

All patients consented to publish personal data in an anonymised form.

\section{Availability of Data and Materials}

All patient-related data were collected by file research from the archives of the Department of Orthopaedics and Trauma Surgery, University of Duisburg-Essen.

\section{Competing Interest}

None of the authors had competing interests.

\section{Authors Contribution}

All authors insured that they substantially contributed to the article and that they are in agreement with form and contents of the manuscript.

\section{References}

1. Choi YR, Lee SJ, Kim JH, Kim TH, Oh CH (2018) Effect of metatarsal osteotomy and open lateral soft tissue procedure on sesamoid position: Radiological assessment. J Orthop Surg Res 13: 11.

2. Nix SE, Vicenzino BT, Collins NJ, Smith MD (2012) Characteristics of foot structure and footwear associated with hallux valgus: A systematic review. Osteoarthritis Cartilage 20: 1059-1074.

3. Hardy RH, Clapham JC (1951) Observations on hallux valgus; based on a controlled series. J Bone Joint Surg $\mathrm{Br}$ 33: 376-391.

4. Piggott $H$ (1960) The natural history of hallux valgus in adolescence and early adult life. J Bone Joint Surg $\mathrm{Br} 42$ : 749-760.

5. Coughlin MJ, Jones CP (2007) Hallux valgus: Demographics, etiology, and radiographic assessment. Foot Ankle Int 28: 759-777.

6. Hollander K, de Villiers JE, Sehner S, Wegscheider K, Braumann KM, et al. (2017) Growing-up (habitually) barefoot influences the development of foot and arch morphology in children and adolescents. Sci Rep 7: 8079.

7. Munteanu SE, Menz HB, Wark JD, Christie JJ, Scurrah KJ, et al. (2017) Hallux Valgus, by nature or nurture? A twin study. Arthritis Care Res (Hoboken) 69: 1421-1428.

8. Okuda H, Juman S, Ueda A, Miki T, Shima M (2014) Factors related to prevalence of hallux valgus in female university students: A cross-sectional study. J Epidemiol 24: 200-208.

9. D'Arcangelo PR, Landorf KB, Munteanu S, Zammit GV, Menz HB (2010) Radiographic correlates of hallux valgus severity in older people. J Foot Ankle Res 3: 20.

10. Popelka $S$, Hromádka R, Vavř́ik $P$, Barták V, Popelka $S$ Jr, et al. (2012) Hypermobility of the first metatarsal bone in patients with rheumatoid arthritis treated by Lapidus procedure. BMC Musculoskelet Disord 13: 148.

11. Coughlin M, Jones CP (2007) Hallux valgus and first ray mobility. A prospective study. J Bone Joint Surg Am 89: 1887-1898.

12. Coughlin MJ, Jones $C P$, Viladot R, Golanó P, Grebing BR, et al. (2004) Hallux valgus and first ray mobility: A cadaveric study. Foot Ankle Int 25: 537-544.

13. Doty JF, Harris WT (2018) Hallux valgus deformity and treatment: A three-dimensional approach. Foot Ankle Clin 23: $271-280$.

14. Jäger M, Schmidt M, Wild A, Bittersohl B, Courtois S, 
et al. (2009) Z-osteotomy in hallux valgus: Clinical and radiological outcome after Scarf osteotomy. Orthop Rev (Pavia) 1: e4.

15. Mani SB, Lloyd EW, Mac Mahon A, Roberts MM, Levine DS, et al. (2015) Modified lapidus procedure with joint compression, meticulous surface preparation, and shearstrain-relieved bone graft yields low nonunion rate. HSS J 11: $243-248$

16. Drummond D, Motley T, Kosmopoulos V, Ernst J (2018) Stability of locking plate and compression screws for lapidus arthrodesis: A biomechanical comparison of plate position. J Foot Ankle Surg 57: 466-470.

17. Plaaß C, Claaßen L, Ettinger S, Daniilidis K, Stukenborg Colsman C (2017) Lapidus arthrodesis. Orthopade 46: 424433.

18. Prissel MA, Hyer CF, Grambart ST, Bussewitz BW, Brigido SA, et al. (2016) A multicenter, retrospective study of early weightbearing for modified lapidus arthrodesis. J Foot Ankle Surg 55: 226-229.

19. Mclnnes BD, Bouché RT (2001) Critical evaluation of the modified lapidus procedure. J Foot Ankle Surg 40: 71-90

20. Patel S, Ford LA, Etcheverry J, Rush SM, Hamilton GA (2004) Modified lapidus arthrodesis: Rate of nonunion in 227 cases. J Foot Ankle Surg 43: 37-42.

21. Sangeorzan BJ, Hansen ST (1989) Modified lapidus procedure for hallux valgus. Foot Ankle 9: 262-266.

22. Thompson IM, Bohay DR, Anderson JG (2005) Fusion rate of first tarsometatarsal arthrodesis in the modified lapidus procedure and flat foot reconstruction. Foot Ankle Int 26: 698-703.

23. Lapidus PW (1934) Operative correction of the metarsusvarus primus in hallux valgus. Surg Gynecol Obstet 54: 183-191.

24. Chauhan D, Bhutta MA, Barrie JL (2011) Does it matter how we measure metatarsal length? Foot Ankle Surg 17: 124127.

25. Kopp FJ, Patel MM, Levine DS, Deland JT (2005) The modified Lapidus procedure for hallux valgus: A clinical and radiographic analysis. Foot Ankle Int 26: 913-917.

26. King CM, Richey J, Patel S, Collman DR (2015) Modified lapidus arthrodesis with crossed screw fixation: Early weightbearing in 136 patients. J Foot Ankle Surg 54: 69-75.

27. Baxter JR, Mani SB, Chan JY, Vulcano E, Ellis SJ (2015) Crossed-screws provide greater tarsometatarsal fusion stability compared to compression plates. Foot Ankle Spec 8: 95-100.
28. Roth KE, Peters J, Schmidtmann I, Maus U, Stephan D, et al. (2014) Intraosseous fixation compared to plantar plate fixation for first metatarsocuneiform arthrodesis: A cadaveric biomechanical analysis. Foot Ankle Int 35: 1209-1216.

29. Garas PK, DiSegna ST, Patel AR (2018) Plate alone versus plate and lag screw for lapidus arthrodesis: A biomechanical comparison of compression. Foot Ankle Spec.

30. Simons P, Fröber R, Loracher C, Knobe M, Gras F, et al. (2015) First tarsometatarsal arthrodesis: An anatomic evaluation of dorsomedial versus plantar plating. J Foot Ankle Surg 54: 787-792.

31. Klos K, Wilde $\mathrm{CH}$, Lange A, Wagner A, Gras F, et al. (2013) Modified lapidus arthrodesis with plantar plate and compression screw for treatment of hallux valgus with hypermobility of the first ray: A preliminary report. Foot Ankle Surg 19: 239-244.

32. Cottom JM, Vora AM (2013) Fixation of lapidus arthrodesis with a plantar interfragmentary screw and medial locking plate: A report of 88 cases. J Foot Ankle Surg 52: 465-469.

33. Liu P, Wu X, Shi H, Liu R, Shu H, et al. (2015) Intramedullary versus extramedullary fixation in the management of subtrochanteric femur fractures: A meta-analysis. Clin Interv Aging 10: 803-811.

34. Asloum Y, Bedin B, Roger T, Charissoux JL, Arnaud JP, et al. (2014) Internal fixation of the fibula in ankle fractures: A prospective, randomized and comparative study: Plating versus nailing. Orthop Traumatol Surg Res 100: S255-S259.

35. Zhang C, Shi Z, Mei G (2015) Locking plate versus retrograde intramedullary nail fixation for tibiotalocalcaneal arthrodesis: A retrospective analysis. Indian J Orthop 49: 227-232.

36. Xie L, Guo X, Zhang SJ, Fang ZH (2017) Locking compression plate distal ulna hook plate fixation versus intramedullary screw fixation for displaced avulsion fifth metatarsal base fractures: A comparative retrospective cohort study. BMC Musculoskelet Disord 18: 405.

37. Donnenwerth MP, Borkosky SL, Abicht BP, Plovanich EJ, Roukis TS (2011) Rate of nonunion after first metatarsalcuneiform arthrodesis using joint curettage and two crossed compression screw fixation: A systematic review. J Foot Ankle Surg 50: 707-709.

38. O'Malley MJ, Sayres SC, Saleem O, Levine D, Roberts $\mathrm{M}$, et al. (2014) Morbidity and complications following percutaneous calcaneal autograft bone harvest. Foot Ankle Int 35: 30-37.

39. Fitzgibbons TC, Hawks MA, McMullen ST, Inda DJ (2011) Bone grafting in surgery about the foot and ankle: Indications and techniques. J Am Acad Orthop Surg 19: 112-120. 